\title{
End-To-End Simulation of Launch Vehicle Trajectories Including Stage Separation Dynamics
}

\author{
Cindy W. Albertson ${ }^{1}$, Paul V. Tartabini ${ }^{2}$, and Bandu N. Pamadi ${ }^{3}$ \\ NASA-Langley Research Center, Hampton, Virginia 23681-2199
}

\begin{abstract}
The development of methodologies, techniques, and tools for analysis and simulation of stage separation dynamics is critically needed for successful design and operation of multistage reusable launch vehicles. As a part of this activity, the Constraint Force Equation (CFE) methodology was developed and implemented in the Program to Optimize Simulated Trajectories II (POST2). The objective of this paper is to demonstrate the capability of POST2/CFE to simulate a complete end-to-end mission. The vehicle configuration selected was the Two-Stage-To-Orbit (TSTO) Langley Glide Back Booster (LGBB) bimese configuration, an in-house concept consisting of a reusable booster and an orbiter having identical outer mold lines. The proximity and isolated aerodynamic databases used for the simulation were assembled using wind-tunnel test data for this vehicle. POST2/CFE simulation results are presented for the entire mission, from lift-off, through stage separation, orbiter ascent to orbit, and booster glide back to the launch site. Additionally, POST2/CFE stage separation simulation results are compared with results from industry standard commercial software used for solving dynamics problems involving multiple bodies connected by joints.
\end{abstract}

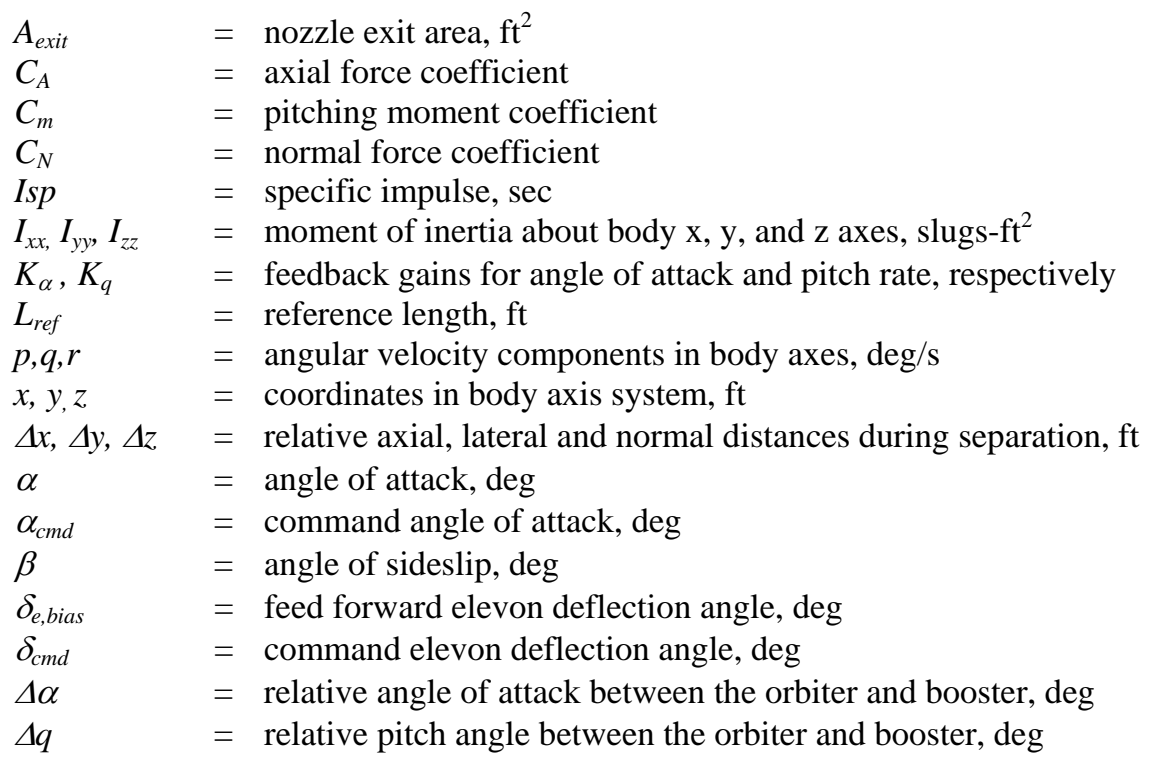

Suffixes

$1,2=$ indices for booster and orbiter, respectively

\footnotetext{
${ }^{1}$ Aerospace Engineer, Vehicle Analysis Branch.

${ }^{2}$ Aerospace Engineer, Vehicle Analysis Branch, Member AIAA.

${ }^{3}$ Aerospace Engineer, Vehicle Analysis Branch, Associate Fellow AIAA.
} 


$\begin{array}{ll}\begin{array}{l}\text { Acronyms } \\ \text { ADAMS }\end{array} & =\text { Automatic Dynamic Analysis of Mechanical Systems } \\ \text { CFE } & =\text { Constraint Force Equation } \\ \text { ConSep } & =\text { Conceptual Separation } \\ \text { DOF } & =\text { Degrees Of Freedom } \\ \text { GLOW } & =\text { Gross Lift-Off Weight } \\ \text { LGBB } & =\text { Langley Glide Back Booster } \\ \text { LOX-H2 } & =\text { Liquid oxygen-liquid hydrogen } \\ \text { NASA } & =\text { National Aeronautics and Space Administration } \\ n m i & =\text { nautical mile } \\ \text { PD } & =\text { Proportional Derivative } \\ \text { POST2 } & =\text { Program to Optimize Simulated Trajectories II } \\ \text { SLS } & =\text { Sea Level Static } \\ \text { TSTO } & =\text { Two-Stage-To-Orbit }\end{array}$

\section{Introduction}

$\mathrm{T}$ HE problem of dynamic separation of multiple bodies within the atmosphere is complex and challenging. One class of stage separation problems involves vehicles that are much smaller than the parent vehicle, such as the separation of the X-15 research vehicle from the B-52 carrier aircraft. ${ }^{1}$ The other class involves the separation of two vehicles of comparable sizes, as in the case of multi-stage reusable launch vehicles where the integrity of each stage is important after separation. A detailed history of work done for both problem classes is given in Ref. 2 .

Recent NASA work on stage separation includes the development of the Constraint Force Equation (CFE) methodology ${ }^{2,3}$ which has been implemented in the Program to Optimize Simulated Trajectories II (POST2), ${ }^{4,5}$ for simulating multibody stage separation dynamics. The CFE implementation in POST2 provides a framework for computing the internal constraint forces and moments acting at joints connecting multiple vehicles. Joint models include fixed, revolute, translational, spherical, and customized joints. The internal constraint forces and moments at the joints can then be applied to each body as additional external forces, together with the modeled external forces and moments due to gravity, aerodynamics, and propulsion. The CFE methodology and its implementation within POST2 provides the capability of simulating complete, seamless, end-to-end launch vehicle trajectories which include generic, multi-body stage separation dynamics.

The objective of this paper is to demonstrate the capability of POST2 with CFE implementation to simulate a complete end-to-end mission, including stage separation. The vehicle configuration selected is the two-stage-toorbit (TSTO) Langley Glide Back Booster (LGBB) bimese configuration described in Ref. 6. The proximity and isolated aerodynamic databases used for the simulation were the same as those used in Ref. 6 . These databases were assembled using wind-tunnel test data from Ref. 7. POST2/CFE simulation results are presented for the entire mission, from lift-off, through stage separation, orbiter ascent to orbit, and booster glide back to the launch site. The runway landing of the booster was not simulated. Additionally, POST2/CFE stage separation simulation results are compared with the results obtained using ConSep/ADAMS. ConSep is a MATLAB ${ }^{\circledR}$ based front end to the ADAMS $^{\circledR}$ (Automatic Dynamic Analysis of Mechanical Systems) solver which is industry standard commercial software.

\section{Vehicle Description}

The TSTO bimese vehicle configuration used in this study consists of a reusable booster and orbiter having the same outer mold line (Fig. 1). The outer mold lines of the booster and orbiter are identical to that of the LGBB small launcher shown in Fig. 2, except that the vehicles do not feature canards. Furthermore, both the booster and orbiter are 4.16 times larger in size than the small launcher. The sizing of the bimese vehicles used in this study was based on the Mach 3 glideback reference configuration developed during the NASA Intercenter Systems Analysis Team effort, which was part of the Space Launch Initiative program. ${ }^{9}$ The vehicles were sized for a 35,000-lb payload to the International Space Station using
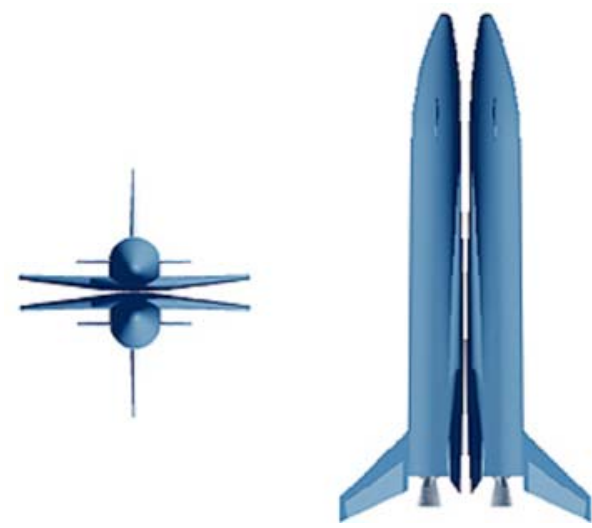

Figure 1. Schematic of the bimese booster and orbiter configuration.

American Institute of Aeronautics and Astronautics 
the INTegrated Rocket Sizing Program. ${ }^{10}$ For the purpose of this study, a single space shuttle main engine class engine was used for each stage.

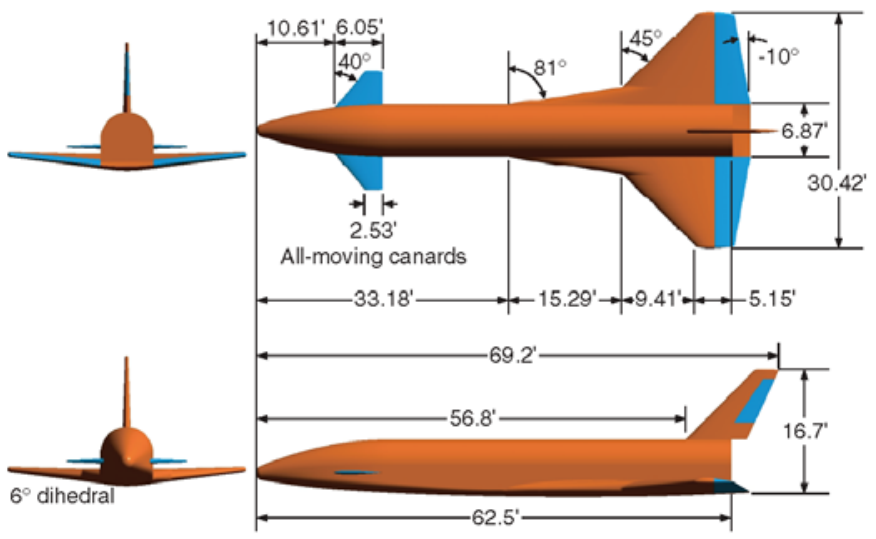

Figure 2. Diagram of the Langley glide back booster (LGBB).

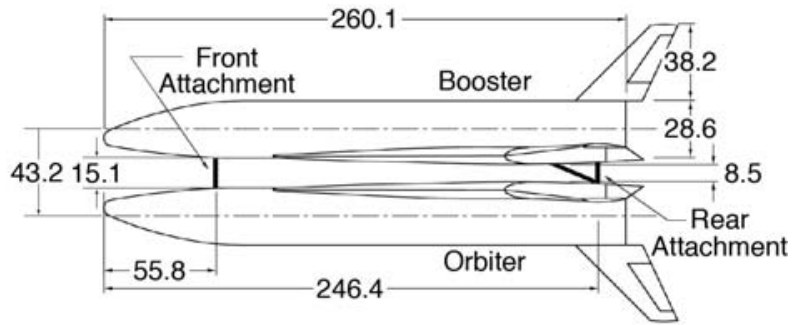

Figure. 3 Booster and orbiter dimensions and attachments (dimensions in feet).
The schematic diagram of the attachment of the orbiter to the booster is shown in Fig. 3. The booster is attached to the orbiter at two joint locations. Before the release, the forward joint is assumed to be a fixed support, and the aft joint is assumed to permit rotation in pitch. These joints and the gap measurements are similar in geometry to the shuttle orbiter and external tank attachment system, except that the rear joint has a pivot linkage that allows the rotation of the booster, relative to the orbiter upon release of the forward joint. This separation sequence is similar to that used in Ref. 11. At separation, the orbiter is operating at full thrust and the booster at no thrust.

The estimated mass properties of the two vehicles at launch and staging are presented in Tables 1 and 2, respectively.

The launch vehicle stack is vertically launched and ascends up to the staging Mach number, using the fuel in the booster (Fig. 4). The vehicles then separate after the booster fuel is exhausted. After separation, the booster returns unpowered to a runway near the launch site while the orbiter continues its ascent up to low earth orbit. Flight conditions at staging are given in Table 3.

Table 1 Mass properties, thrust, and coordinates for the LGBB-bimese vehicle at launch.

\begin{tabular}{|c|c|c|c|}
\hline Property & Orbiter (includes payload) & Booster & Total (Stack) \\
\hline GLOW, lbm & $2,896,596$ & $2,755,722$ & $5,652,318$ \\
\hline Dry weight, lbm & 576,602 & 435,728 & $1,012,330$ \\
\hline Propellant weight, lbm & $2,319,994$ & $2,319,994$ & $4,639,988$ \\
\hline Thrust, lbf (SLS) & $3,598,296$ & $3,598,296$ & $7,196,592$ \\
\hline Isp (vacuum), sec & 453.5 & 453.5 & 453.5 \\
\hline A $_{\text {exit }}, \mathrm{ft}^{2}$ & 400.8 & 400.8 & 801.6 \\
\hline Longitude, deg & 280.0 & 280.0 & 280.0 \\
\hline Latitude, deg & 28.5 & 28.5 & 28.5 \\
\hline Flight path angle, deg & 90.0 & 90.0 & 90.0 \\
\hline
\end{tabular}

\section{POST2/CFE Simulation Description}

To simplify modeling within POST2, the orbiter and booster stack were initially modeled as a single vehicle stack with two liquid oxygen-liquid hydrogen (LOX-H2) rocket engines operating from lift-off until staging. After lift-off, the vehicle stack was controlled using pitch angles until 5 seconds before separation, at which point, the vehicle stack was guided using aerodynamic angles to adjust the angle of attack to zero at separation. This was done to help keep the vehicles within the proximity aerodynamic database parameter limits during stage separation. Staging begins when the booster portion of the vehicle stack has exhausted its propellants. Because the booster and orbiter were sized with equal propellant weights, staging begins when one half of the total propellants of the vehicle stack have been consumed. The booster and orbiter were then modeled as two separate vehicles prior to separation 
with the booster positioned symmetrically (180 degrees in roll) relative to the orbiter. Additionally, the engine thrust of the booster was set to zero so that it returned to the vicinity of the runway unpowered, while the orbiter operated with one engine at full thrust. The CFE methodology was exercised by initially modeling the rear attachment between the vehicles (Fig. 3) as a fixed joint. (Only one joint is allowed between two vehicles to avoid over- constraining the simulation.) At the beginning of staging, the fixed joint was changed to a revolute joint which was free to rotate in the pitch plane. Once the relative pitch between the vehicles reached $1.0 \mathrm{deg}$, the rotational joint became a free joint and the vehicles were allowed to move apart in response to aerodynamic forces and thrust from the orbiter engine.

Table 3. Staging conditions for the LGBBbimese vehicle.

\begin{tabular}{|c|c|}
\hline Mach & 3.79 \\
\hline Altitude, $\mathrm{ft}$ & 93,975 \\
\hline Latitude, deg & 28.7 \\
\hline Longitude, deg & 280.2 \\
\hline Relative velocity, ft/s & 3741.0 \\
\hline $\begin{array}{c}\text { Relative flight path } \\
\text { angle, deg }\end{array}$ & 34.57 \\
\hline Angle of attack, deg & 0.0 \\
\hline Dynamic pressure, psf & 308.0 \\
\hline
\end{tabular}

Table 2 Mass Properties and thrust at Staging for the LGBB-bimese vehicle.

\begin{tabular}{|c|c|c|}
\hline Property & Orbiter & Booster \\
\hline Total weight, lbm & $2,896,596$ & 435,728 \\
\hline Dry weight, lbm & 576,602 & 435,728 \\
\hline Propellant weight, lbm & $2,319,994$ & 0 \\
\hline Thrust, lbf & $4,434,418$ & 0 \\
\hline$x$ cg, $\mathrm{ft}$ & 114.2 & 197.7 \\
\hline Ixx, slugs- $\mathrm{ft}^{2}$ & $20,800,000$ & $4,880,000$ \\
\hline Iyy, slugs- $\mathrm{ft}^{2}$ & $244,000,000$ & $57,300,000$ \\
\hline Izz, slugs- $\mathrm{ft}^{2}$ & $244,000,000$ & $57,300,000$ \\
\hline
\end{tabular}

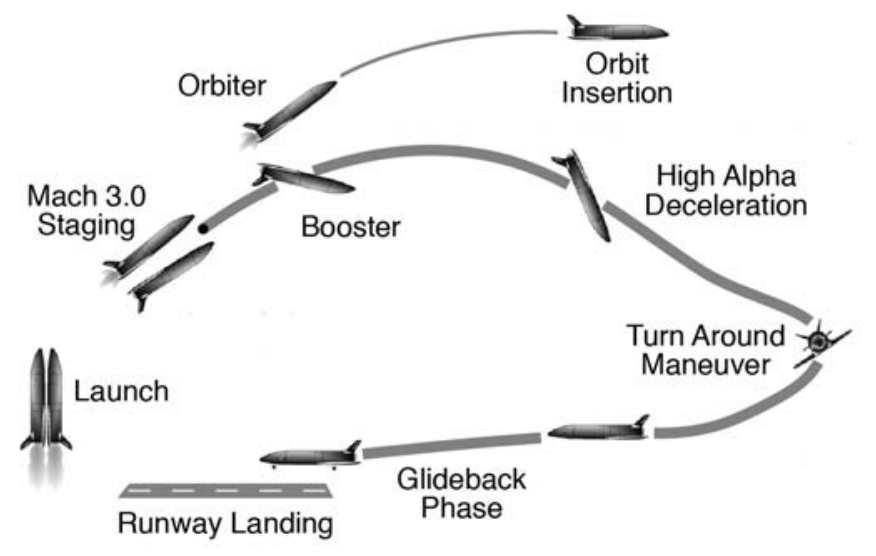

Figure 4. Flight profile for the bimese configuration.

Once the axial separation distance between the vehicles exceeded the parameter limits of the aerodynamic database (2.1 vehicle lengths), staging was assumed to be complete and the orbiter was then guided to a 50 nautical mile (nmi) altitude

(303,800 ft) with an inclination of 51.6 deg using pitch angles. Once the specified orbital velocity was reached $(25,855 \mathrm{ft} / \mathrm{sec})$, the orbiter engine was turned off and the orbiter portion of the simulation was terminated. Meanwhile, the unpowered booster was guided back to the launch site using aerodynamic angles (bank angles and angles of attack). The landing target was the longitude and latitude of the launch site. The simulation was terminated when the booster had returned the launch site within 1 mile of the launch site at $1000 \mathrm{ft}$. The alignment with the runway and landing were not simulated. Additionally, aerodynamic heating was not calculated.

Additional ground rules and assumptions included: (1) WGS-1984 oblate Earth geometric and gravity models including harmonics through J4, (2) 1976 US standard atmosphere model, (3) no atmospheric winds, (4) an acceleration limit of $3 \mathrm{~g}$, and (5) LOX-H2 rocket engines with Isp vac $=453$ sec. A complete list of ground rules, assumptions, and constraints is provided in Table 4.

\section{Aerodynamic Databases}

Three separate aerodynamic databases were used for the end-to-end mission simulation. These databases included a vehicle stack ascent database, a stage separation proximity database, and an isolated vehicle database. The vehicle stack ascent database was essentially the isolated vehicle database with a multiplication factor of two applied to the drag coefficients. The stage separation and isolated vehicle databases were obtained from wind tunnel tests described in Ref. 7. 
Table 4. Ground rules, assumptions, and constraints for the LGBB-Bimese Vehicle.

\begin{tabular}{|l|l|}
\hline 1 & WGS-1984 oblate Earth geometric and gravity models including harmonics through J4 \\
\hline 2 & 1976 US Standard Atmosphere model \\
\hline 3 & No atmospheric winds \\
\hline 4 & Acceleration limit of $3 \mathrm{~g}$ \\
\hline 5 & LOX-H2 rocket engine on each vehicle, Isp vac $=453 \mathrm{sec}$ \\
\hline 6 & $\begin{array}{l}\text { Fuel and oxidizer are cross-fed from the booster tanks to both the booster and orbiter engines during } \\
\text { vehicle stack ascent }\end{array}$ \\
\hline 7 & Staging occurs when booster fuel and oxidizer is exhausted \\
\hline 8 & Orbital insertion for the orbiter occurs when delta $\mathrm{v}=25855 \mathrm{ft} / \mathrm{sec}$, altitude $=50$ nmi \\
\hline 9 & $\begin{array}{l}\text { Landing target satisfied when the booster reaches the launch site at 28.5deg latitude and } 280.0 \text { deg. } \\
\text { longitude, } \pm \text { 0.0145 deg. (or } \pm \text { mile) at an altitude of 1000 ft }\end{array}$ \\
\hline 10 & $\begin{array}{l}\text { 3-DOF from launch to staging, 6-DOF during separation, 3-DOF after axial separation distance } \\
\text { exceeds 2.1 vehicle lengths }\end{array}$ \\
\hline
\end{tabular}

The longitudinal stage-separation aerodynamic coefficients depend on the relative location of the two vehicles as characterized by three variables: $\Delta \mathrm{x}, \Delta \mathrm{z}$, and $\Delta \alpha$. The dependence of stage separation aerodynamic coefficients on $\Delta \mathrm{x}, \Delta \mathrm{z}$, and $\Delta \alpha$ is in addition to their usual dependence on Mach number and $\alpha$. Sketches showing the relative locations of the two vehicles in the wind-tunnel tests and corresponding orientations in flight are presented in Fig. 5. During wind tunnel simulation, the free stream velocity vector is the same for both vehicles, assuming a uniform wind tunnel test core (Fig 5a). However, during flight the velocity vectors of the vehicles are independent after separation. POST2/CFE simulation results indicate that the velocity vectors are within 0.6 degrees of each other during the proximity portion of flight. Therefore, the relative pitch angle, $\Delta \theta$, and $\Delta \alpha$ are approximately equal (Fig 5b) and the wind tunnel-derived proximity aerodynamic database is considered to be applicable. The separation distances $\Delta \mathrm{x}$ and $\Delta \mathrm{z}$ are measured with respect to the orbiter coordinate system. Note that $\Delta \mathrm{x}$ is negative when the booster is aft of the orbiter. Sample aerodynamic data are presented in Fig. 6.

The stage separation proximity aerodynamic database is limited to

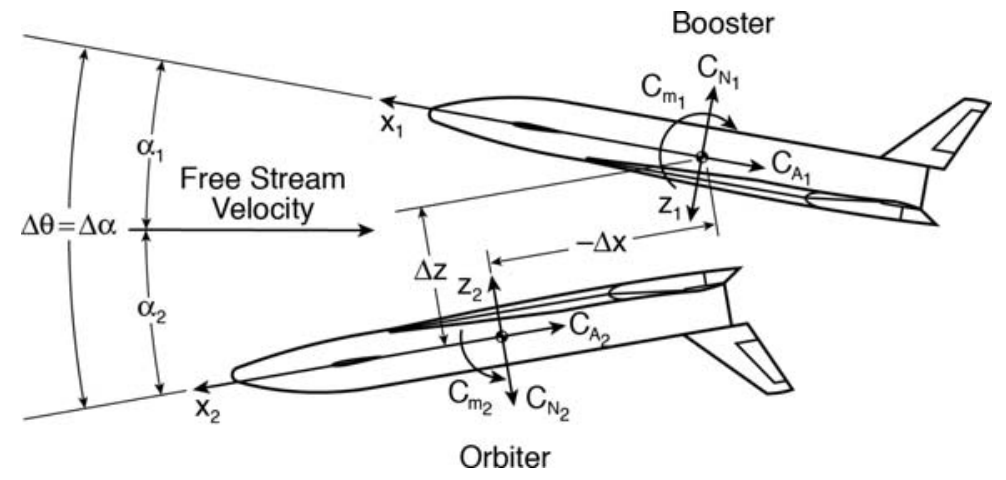

a) Wind tunnel testing.

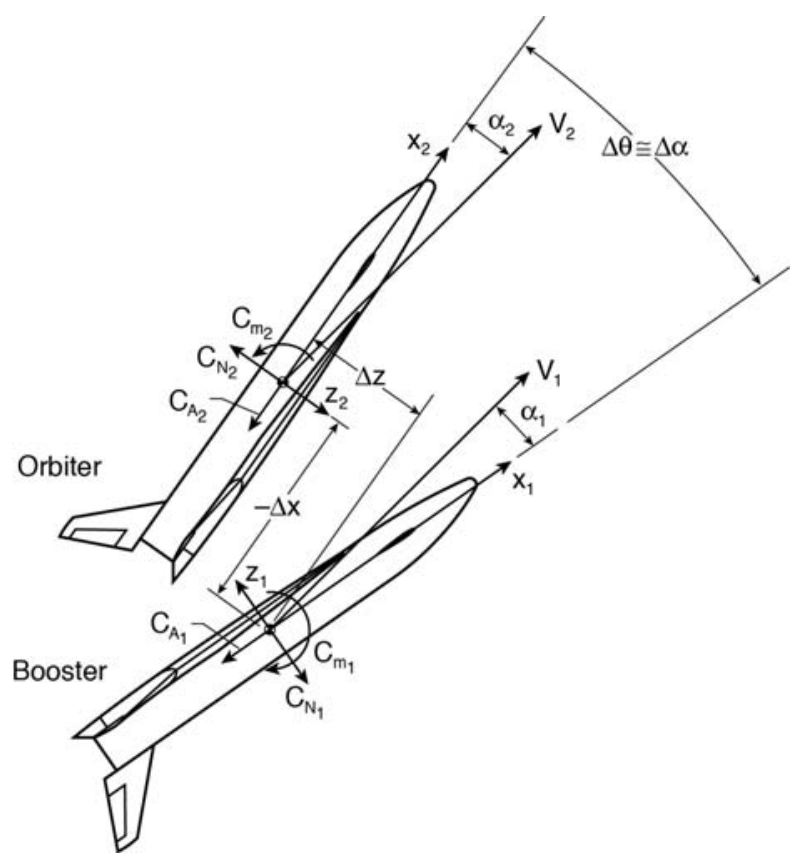

b) Flight.

Figure 5. Relative locations of the booster and orbiter in proximity. 5

American Institute of Aeronautics and Astronautics 
angles of attack of 0 and 5 degrees with $\Delta \alpha$ of 0 and 5 degrees (Fig. 5) for both the booster and orbiter. In order to keep the vehicles in this range, a closed-loop proportional derivative (PD) feedback control system was implemented in POST2 to control the elevons of both the booster and orbiter during separation (Fig. 7), as done in Ref. 6. The elevon deflections were controlled by a commanded angle of attack, $\alpha_{\mathrm{cmd}}$, instantaneous angle of attack, $\alpha$, elevon feed forward gains, and pitch rate feedback gains. In this study, the feed forward bias, $\delta_{\mathrm{e}, \mathrm{bias}}$, was not used. The full range of elevon deflection for which isolated LGBB test data were obtained is - 30 to 20 deg.

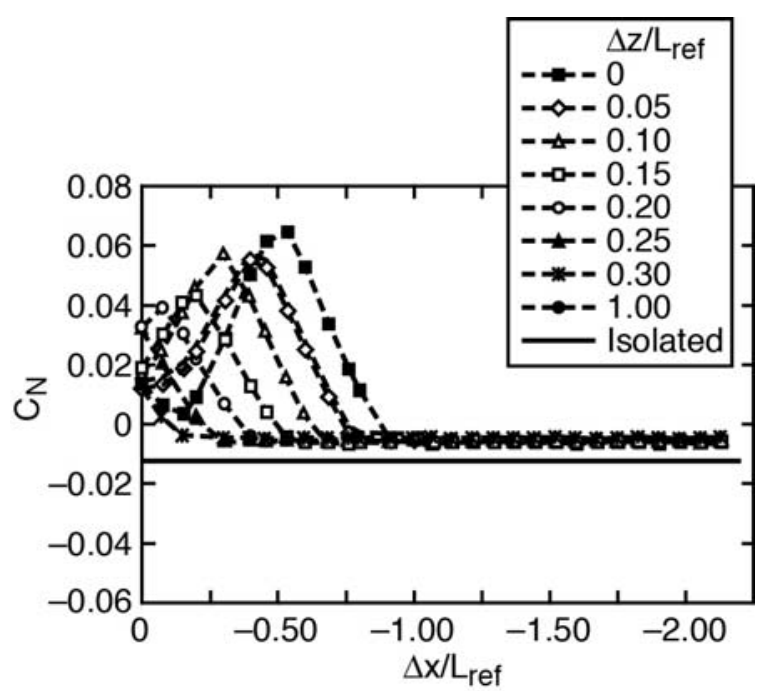

Figure 6. Sample of the aerodynamic database showing the variation of the orbiter normal force coefficient with $\Delta x / L_{\text {ref }}$ and $\Delta z / L_{\text {ref }}$ at Mach 3 for $\alpha=0$ and $\Delta \alpha=0$ deg.

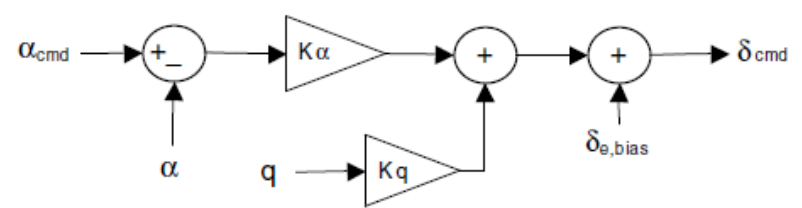

Figure 7. Feedback control system implemented in POST2.

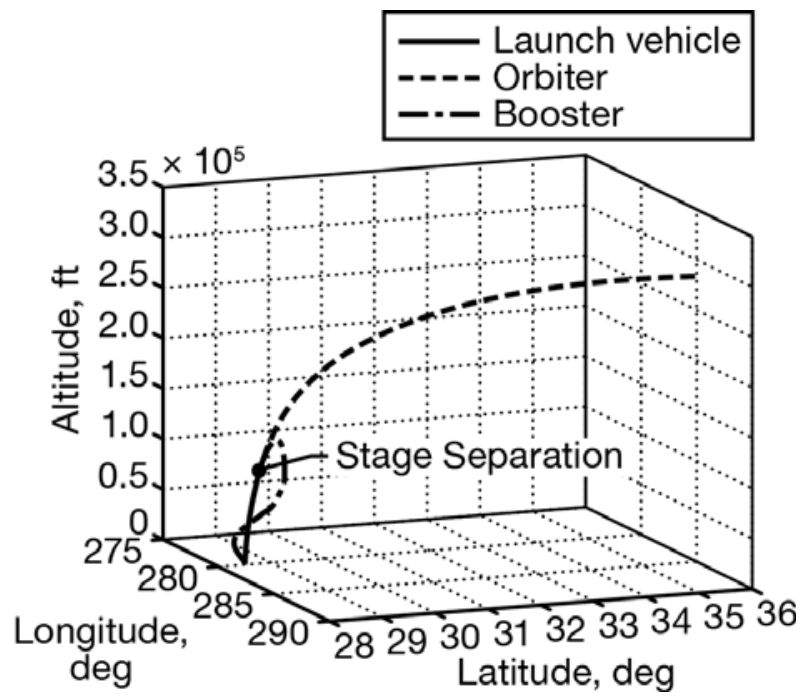

Figure 8. Three-dimensional trajectory plot.
The values of $K_{\alpha}$ and $K_{q}$ were determined by trial and error to constrain the vehicles within the aerodynamic database limits. The values of these parameters used in the simulation are presented in Table 5.

The proximity database was limited to separation distances between 0 and 2.1 vehicle lengths. Once the vehicles were beyond 2.1 vehicle lengths apart, the isolated vehicle aerodynamic database was used.

Table 5. Feedback control system settings.

\begin{tabular}{|c|c|c|c|}
\hline Vehicle & $\mathrm{K}_{\alpha}$ & $\mathrm{K}_{\mathrm{q}}$ & $\alpha_{\text {cmd }}(\mathrm{deg})$ \\
\hline Booster & -15 & 38 & 5 \\
\hline Orbiter & -15 & 28 & 0 \\
\hline
\end{tabular}

\section{Results}

\section{A. Complete Mission}

POST2/CFE trajectory results are shown for the complete mission in terms of altitude vs. latitude and longitude in Fig. 8. The launch vehicle stack ascended from the launch location at Kennedy Space Center (28.5 deg latitude, 280 deg longitude) up to the staging conditions, after which the booster and orbiter separated. The booster trajectory shows the booster returning to the launch location while the orbiter continued to orbit.

Trajectory parameters as a function of time are shown for the complete mission in Figs. 9 through 13. These parameters include altitude, Mach number, weight, thrust, and flight path angle. The orbiter engine

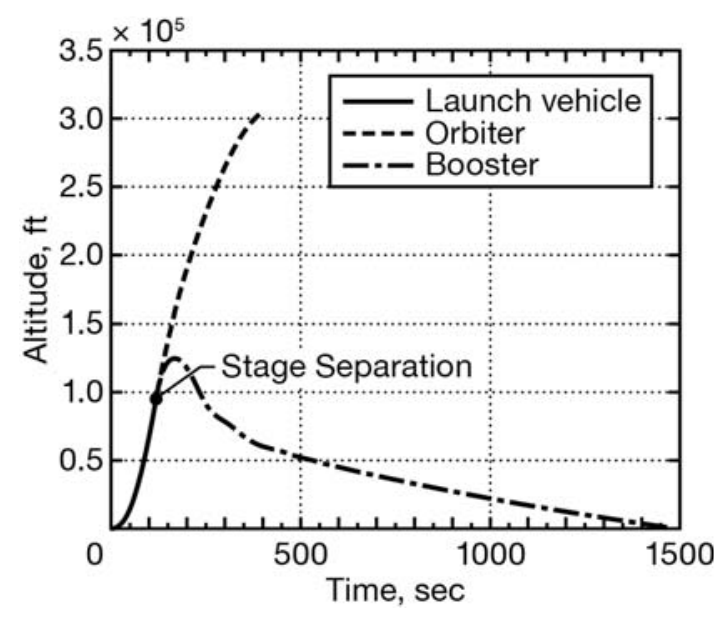

Figure 9. Altitude vs. time. 
was shut down once the altitude target of $50 \mathrm{nmi}(303,000 \mathrm{ft})$ is satisfied at approximately 392 seconds after launch.

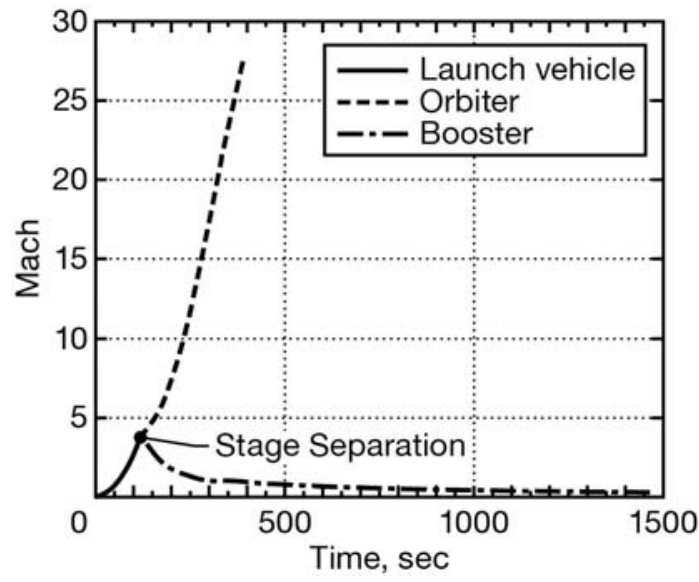

Figure 10. Mach number vs. time.



Figure 12. Thrust vs. time.

\section{B. Stage Separation Simulation}

Stage separation results for the end-to-end simulation are presented in Figs. 14 and 15. These results were obtained using the feedback control system depicted in Fig. 7 to keep the vehicles within the aerodynamic database limits. Staging began after the booster fuel was depleted near Mach 3.8 (Table 3). The vehicles separated once the relative pitch between vehicles reached $1.0 \mathrm{deg}(\mathrm{t}=119 \mathrm{sec})$. Separation distance in terms of axial and normal distance is shown

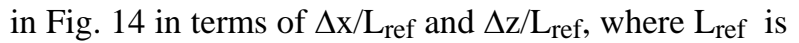
the vehicle length of $260.1 \mathrm{ft}$. The angle of attack variations, shown in Fig. 15, indicate that the orbiter and booster were within the angle of attack limits of the proximity database.

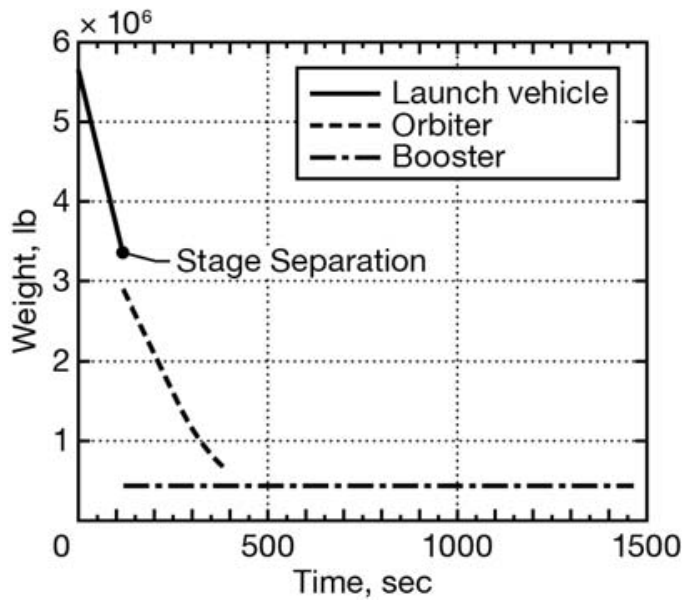

Figure 11. Weight vs. time.

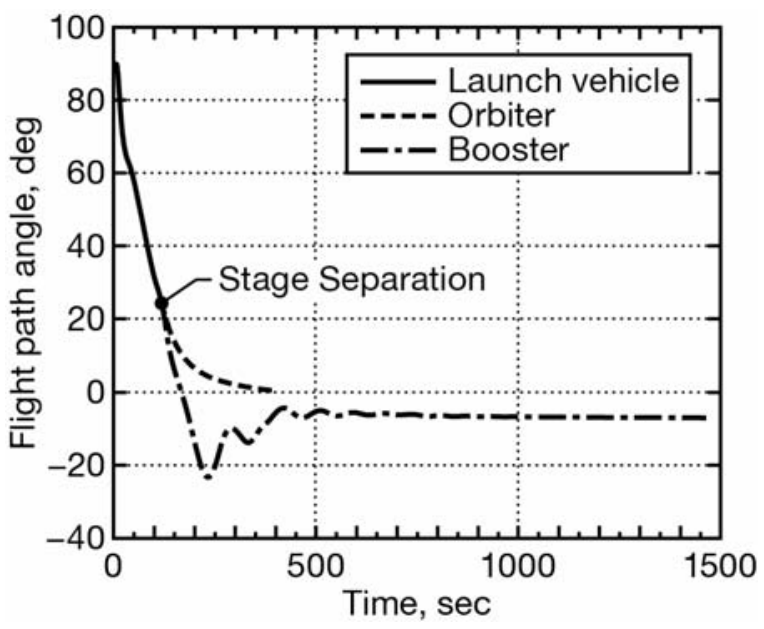

Figure 13. Relative flight path angle vs. time.

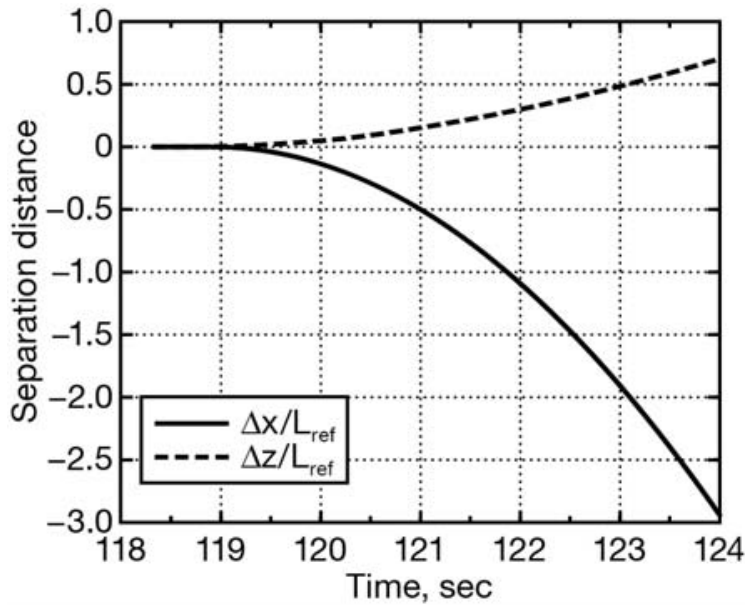

Figure 14. Separation distance between booster and orbiter. 


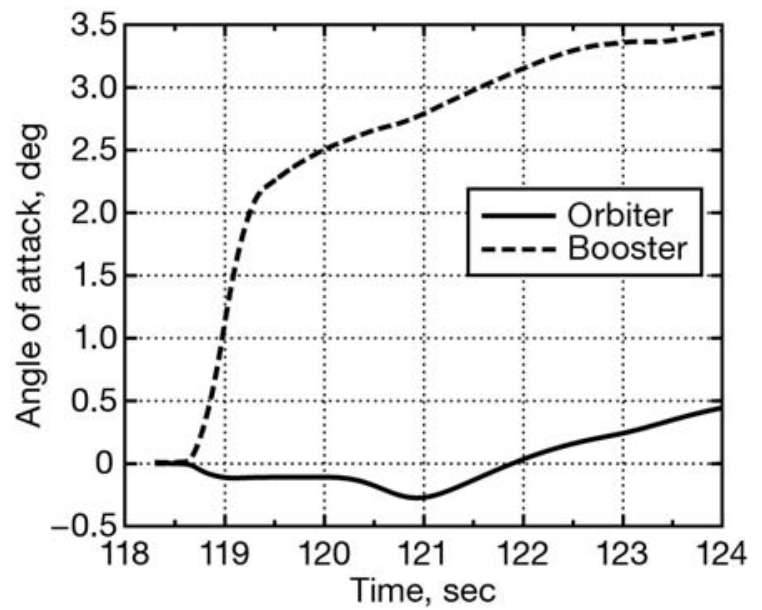

Figure 15. Booster and orbiter angle of attack during stage separation.

Table 6. Mass Properties and thrust used for ConSep/ADAMS comparison at Mach 3 staging.

\begin{tabular}{|c|c|c|}
\hline Property & Orbiter & Booster \\
\hline Weight, lbm & $2,909,000$ & 300,000 \\
\hline Total thrust, lbf & $4,879,000$ & 0 \\
\hline$x$ cg, $\mathrm{ft}$ & 130.0 & 197.6 \\
\hline Ixx, slugs- $\mathrm{ft}^{2}$ & $20,900,000$ & $3,360,000$ \\
\hline Iyy, slugs- $\mathrm{ft}^{2}$ & $245,000,000$ & $39,400,000$ \\
\hline Izz, slugs- $\mathrm{ft}^{2}$ & $245,000,000$ & $39,400,000$ \\
\hline
\end{tabular}

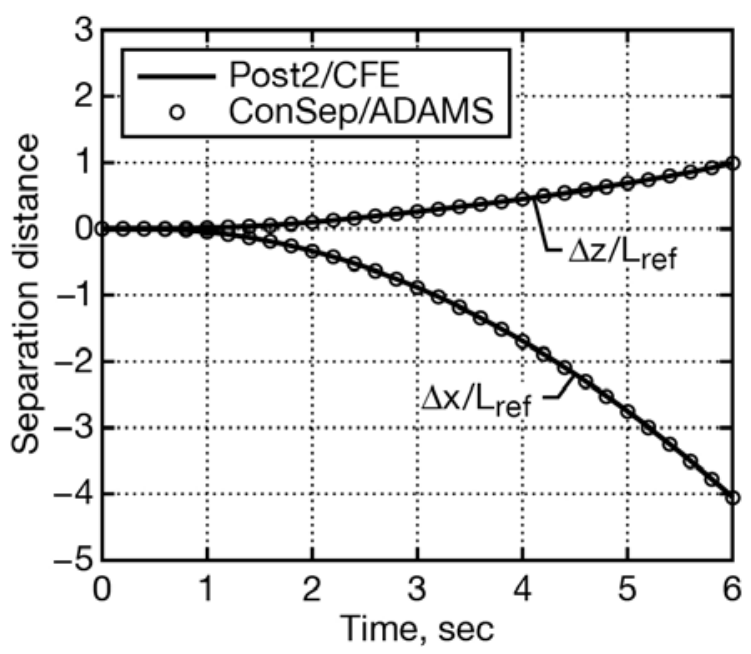

Figure 16. Comparison of POST2/CFE and ConSep/ADAMS separation distances.
Table 7. Staging conditions used for ConSep/ADAMS comparison.

\begin{tabular}{|c|c|}
\hline Mach & 3.0 \\
\hline Altitude, ft & 85,000 \\
\hline Latitude, deg & 28.7 \\
\hline Longitude, deg & 280.2 \\
\hline Relative velocity, ft/sec & 2921.6 \\
\hline Relative flight path angle, deg & 53.0 \\
\hline Angle of attack, deg & 0.0 \\
\hline Dynamic pressure, psf & 287.8 \\
\hline
\end{tabular}

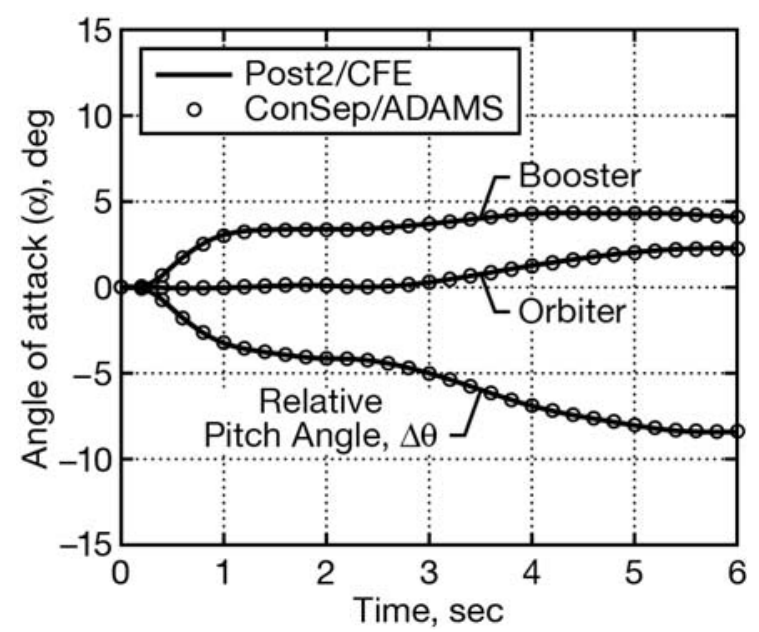

Figure 17. Comparison of POST2/CFE and ConSep/ADAMS angles of attack after stage separation.

\section{Comparison of POST2/CFE Stage Separation with ConSep/ADAMS}

To provide confidence in the POST2/CFE separation results, a separate, isolated, stage separation case was run independent of the end-to-end case and compared with the results obtained using ConSep/ADAMS. Both the POST2/CFE and ConSep/ADAMS cases were run at the same Mach 3 staging conditions given in Ref. 6 and listed in tables 6 and 7. ConSep is a MATLAB ${ }^{\circledR}$ based front end to the $\mathrm{ADAMS}^{\circledR}{ }^{8}$ solver which is industry standard commercial software for solving dynamics problems involving multiple bodies connected by joints. The user does not have to input the governing equations of motion to ADAMS for vehicle motion during stage separation but needs to provide the mathematical models of the aerodynamic and other external forces/moments acting on each of the vehicles during stage separation. The ADAMS code assembles coupled, constrained equations of motion for each vehicle, based on the user supplied inputs, and generates solutions to those equations. The mass properties and thrust used for this case at Mach 3 staging are given in Table 6. Staging

8

American Institute of Aeronautics and Astronautics 


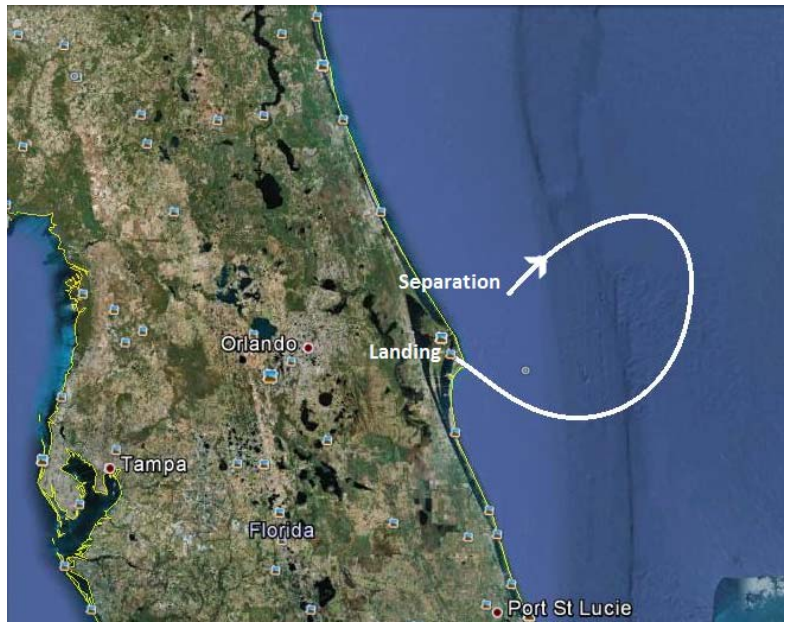

Figure 18. Latitude vs. longitude for the booster as it returns to the launch site off the Florida coast.

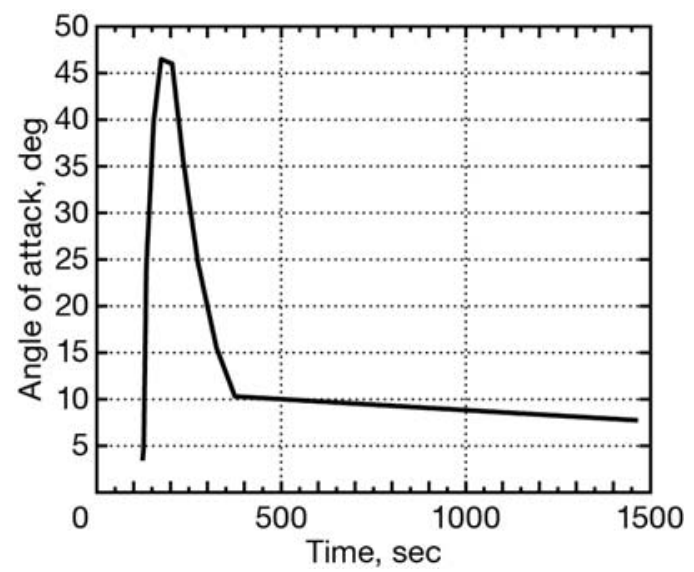

Figure 19. Angle of attack vs. time for the booster as it returns to the launch site.

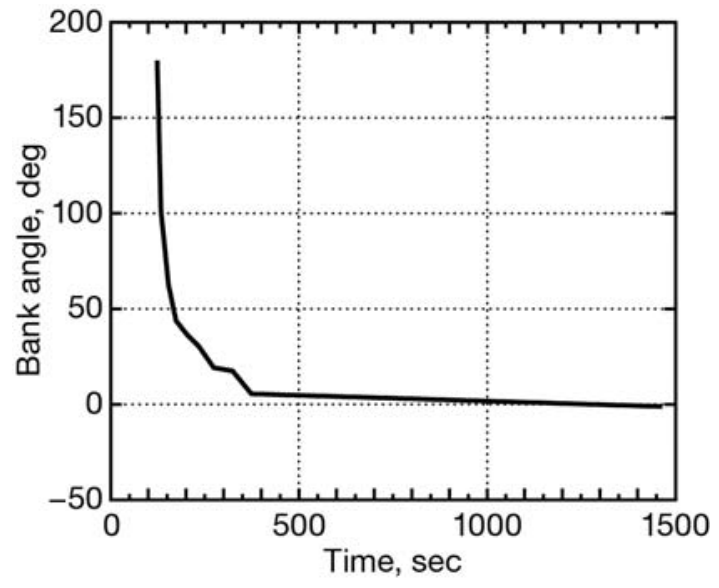

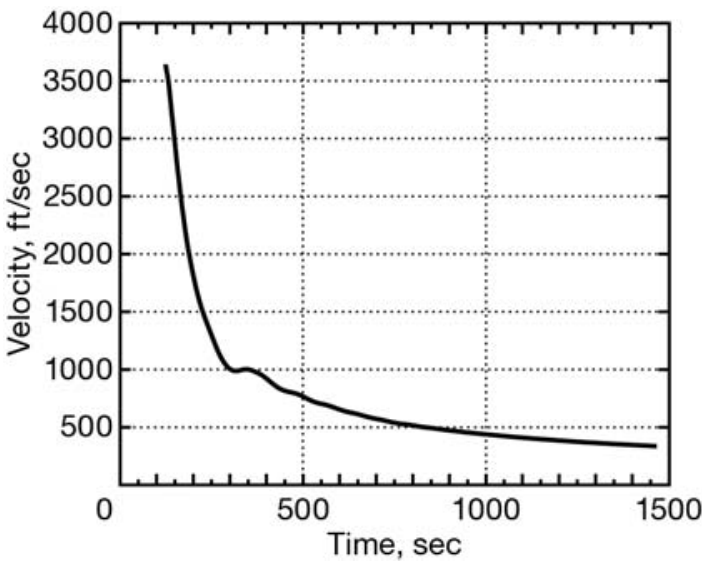

Figure 21. Velocity vs. time for the booster as it returns to the launch site.

conditions for the comparison are given in Table 7.

Results are shown from POST2/CFE (solid lines) and ConSep/ADAMS (symbols) in Figs. 16 and 17. These results were obtained using the feedback control system depicted in Fig. 7. Fig. 16 shows the separation distance between the orbiter and booster in terms of $\Delta \mathrm{x} / \mathrm{L}_{\mathrm{ref}}$ and $\Delta \mathrm{z} / \mathrm{L}_{\text {ref }}$ over a 6 second period after separation. The POST2/CFE separation distances show excellent agreement with ConSep/ADAMS. Fig. 17 shows the angle of attack of the orbiter and booster obtained from POST2/CFE and ConSep/ADAMS. Again the results from the two methods show excellent agreement. This comparison provided the needed confidence that POST2/CFE correctly simulated the separation dynamics for the complete, end-to-end bimese mission.

\section{Booster decent and return to runway}

After separation near 28.7 deg latitude and $280.2 \mathrm{deg}$ longitude (Fig. 18), the booster descended unpowered, following a clockwise trajectory back to the runway. The booster was guided using aerodynamic and bank angle steering, to a target of 28.5 deg latitude and 280.0 deg longitude, $\pm 0.0145 \mathrm{deg}$ (or \pm 1 mile) at an altitude of $1000 \mathrm{ft}$. The angles of attack and bank angles used to guide the booster are shown in Figs 19 and 20, respectively. The maximum booster acceleration remained below $1.6 \mathrm{~g}$ during this flight phase. Aerodynamic heating was not investigated. The vehicle approached the launch site runway at approximately $300 \mathrm{ft} / \mathrm{sec}$, as indicated in Fig. 21.

Figure 20. Bank angle vs. time for the booster as it returns to the launch site. 


\section{Concluding Remarks}

The capability of POST2/CFE to simulate a complete, seemless, end-to-end launch vehicle mission has been demonstrated for an in-house TSTO LGBB bimese configuration. The simulation was performed for the entire mission, from lift-off of the bimese vehicle stack, through stage separation at approximately Mach 3.8, orbiter ascent to orbit, and booster glide back to the launch site. Additionally, POST2/CFE results were validated by running separate, isolated, stage separation case and comparing with the results of Ref. 6 which were obtained using ConSep/ADAMS.

\section{Acknowledgments}

The authors gratefully acknowledge Matthew D. Toniolo and Christopher D. Karlgaard for their help with the POST2/CFE implementation, Peter F. Covell for his help with the bimese geometry and mass properties, and Anne C. Rhodes for her help with preparing the figures for publication.

\section{References}

${ }^{1}$ Taylor, R. T., and Alford, W. J., Jr., A wind tunnel investigation of the carry loads and mutual interference effects of 1/40-scale models of the X-15 and B-52 airplanes in combination, NASA TM X-184, December 1959.

${ }^{2}$ Tartabini, P. V., Roithmayr, C., Toniolo, M. D., Karlgaard, C. D., and Pamadi, B. N., "Modeling Multibody Stage Separation Dynamics Using Constraint Force Equation Methodology,” Journal of Spacecraft and Rockets, Vol. 48, No. 4, 2011, pp. 573-583.

${ }^{3}$ Toniolo, M. D., Tartabini, P. V., Pamadi, B. N., and Hotchko, N. J., "Constraint Force Equation Methodology for Modeling Multi-Body Stage Separation Dynamics,” AIAA Paper 2008-0219, 2008.

${ }^{4}$ Brauer, G. L., Cornick, D. E., and Stevenson, R., "Capabilities and Applications of the Program to Optimize Simulated Trajectories (POST),” NASA CR-2770, 1977.

${ }^{5}$ Striepe, S.A., Powell, R. W., Desai, P. N., Queen, E. M, Brauer, G. L., Cornick, D. E., Olson, D. W., Peterson, F. M., Stevenson, R., Engel, M, C., Marsh, S. M., and Gromko, A. M., Program to Optimize Simulated Trajectories (POST II), Vol. 2: Utilization Manual, Ver. 1.1.7, NASA Langley Research Center, Hampton, VA, July 2002.

${ }^{6}$ Pamadi, B. N., Neirynck, T. A., Covell, P. F., Hotchko, N. J., and Bose, D. M., Simulation and Analyses of Two-Stage Reusable Launch Vehicles, Journal of Spacecraft and Rockets, Vol. 44, No. 1, January-February 2007, pp. 66-80.

${ }^{7}$ Murphy, K. J., Buning, P. G., Pamadi, B. N., Scallion, W. I., and Jones, K. M., "Status of Stage Separation Tool Development for Next Generation Launch Vehicle Technologies,” AIAA Paper 2004-2595, 2004.

${ }^{8}$ Anon., Using ADAMS/Solver, Mechanical Dynamics, Inc., Mesa, AZ, 1999.

${ }^{9}$ NASA's Space Launch Initiative: The Next Generation Launch Technology Program, FS-2003-05-63-MSFC, May 2003.

${ }^{10}$ Lynn, E., "INTROS INTegrated Rocket Sizing Program, Version 4.2, October 2007.

${ }^{11}$ Naftel, J. C., and Powell, R. W., Analysis of the Staging Maneuver and Booster Glideback Guidance for a Two-Staged, Winged, Fully Reusable Launch Vehicle. NASA TP-3335, 1993. 